\title{
Oxidised Low Density Lipoprotein (LDL) Modification with Statin Therapy is Associated with Reduction in Carotid Stenosis
}

\author{
Elias Skopelitis, Dimitrios Levisianou, \\ Helen Lydataki and Sofoklis Kougialis \\ Additional information is available at the end of the chapter \\ http://dx.doi.org/10.5772/57188
}

\section{Introduction}

\subsection{Carotid stenosis and atheromatous process}

Carotid artery stenosis due to atherosclerosis is a major complication of hyperlipidemia, diabetes mellitus and hypertension. Moreover, the extent of carotid intima media thickness is a measure of atheromatosis and therefore of cardiovascular disease (CVD).

The effect of cholesterol in the process of atheromatosis is now well established. High levels of total cholesterol, as well as of low-density lipoprotein (LDL), very low-density lipoprotein (VLDL), intermediate-density lipoprotein (IDL), lipoprotein a (Lp- $\alpha)$, and triglycerides, coupled with decreased levels of high-density lipoprotein (HDL) are responsible for the creation of atheromatous plaques [1-3]. Of the above factors, LDL cholesterol, and especially the oxidized LDL is considered as the most important contributor of atheromatosis [4].

The atheromatous process is completed in the following three stages:

1. In the first stage, LDL cholesterol enters the vessel wall, binds to gluxosaminoglucanes, which are part of the extracellulat matrix of the intima. This binding is facilitated by apolipoprotein B-100 (ApoB-100). The accumulation of LDL in the vessel wall contributes to the formation of fatty strikes. Following LDL adhesion in the vessel wall, it undergoes oxidation by free radicals produced locally, the molecule is altered and chemokines are produced by adjacent vessel wall cells, such as MCP - 1, together with growth factors, which are responsible for the accumulation of monocytes and macrophages. The latter, 
cause further oxidation of LDL, resulting in negative charge, recognition by scavenger receptors on macrophage membrane and increased uptake of LDL inside the macrophages, as these receptors are not inhibited by increased intracellular concentration of cholesterol. The final result is an enormous accumulation of LDL in the macrophages, which are transformed to foamy cells. These cells represent the first step in the atheromatous process [5] (figure 1).

2. During the second stage, the atheromatous plaque is formed. Foamy cells produce growth factors and together with oxidized LDL result to the attraction of smooth muscle cells. The latter, are then differentiated to fibroblasts and start producing collagen. This collagen covers foamy cells, which either are destroyed or are forced to apoptosis. The final result is the formation of a pool of extracellular cholesterol trapped under a fibrous capsid (figure 2). The part which is close to the yet intact vessel wall is the active one of the plaque, where the foamy cells are produced. As the plaque extents to the inner layers of the vessel wall, the point of foamy cell formation becomes instable and may cause rapture of the plaque [5] (figure 3).

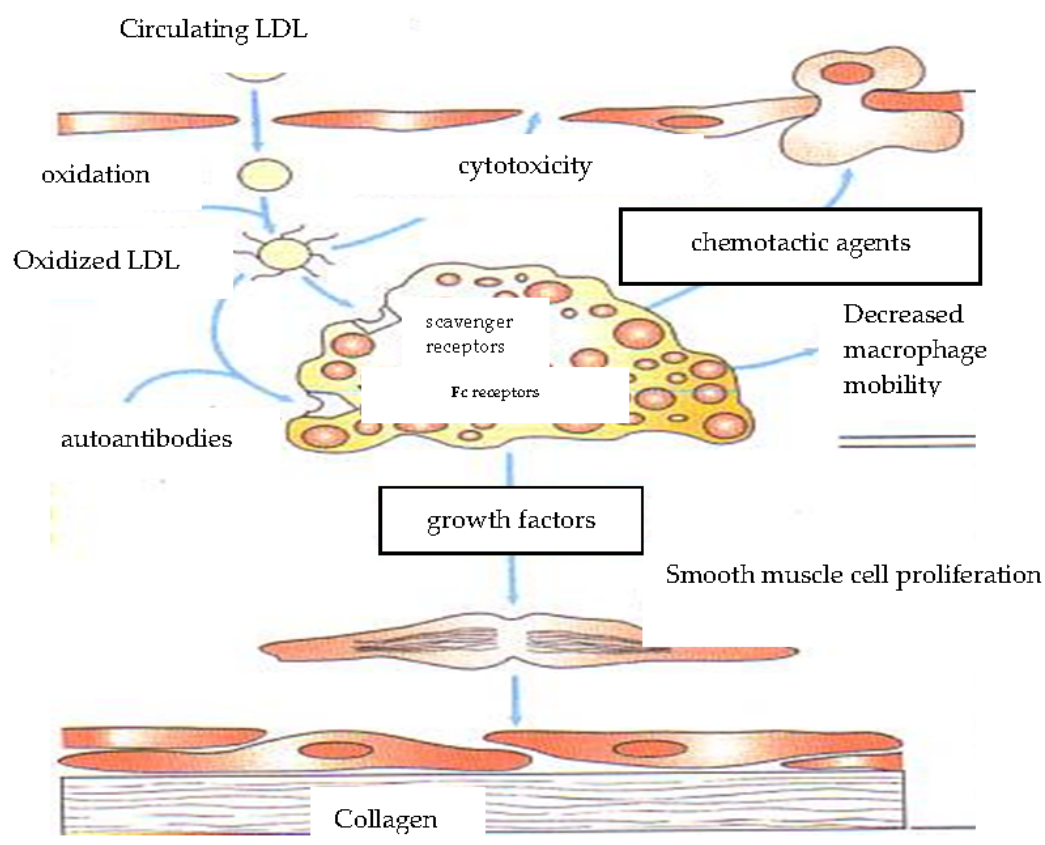

Figure 1. Atherogenesis. Fatty strikes are characterized by macrophages containing an excess of lipids (foamy cells). Foamy cells are derived by blood monocytes which are attracted to vessel intima and start phagocytosing lipoproteins, such as oxidized LDL. The convertion of fatty strike to atheroma depends on proliferation and differentiation of smooth muscle cells to fibroblasts. The latter produce collagen resulting in intima thickening. As the lesion extents further, foamy cells are destroyed releasing large amounts of cholesterol trapped in a fibrous capsid. The active site of atheroma is the point which is adjacent to normal endothelium, where foamy cells are formed (adopted from Durrington \& Sinderman, 2002). 
3. In the third stage, that of the complicated lesion, the rapture of the fibrous capsid of the atheromatous plaque leads to massive evacuation of the cholesterol reservoir. The artery may occult due to the accumulation of platelets and clotting, leading to infarction (figure 4). If not so, then the plaque will be further enlarged [5].

Avoiding the formation and the instability of the atheromatous plaque is top priority for patients at risk for cardiovascular events. Statins may contribute towards this direction $[6,7]$

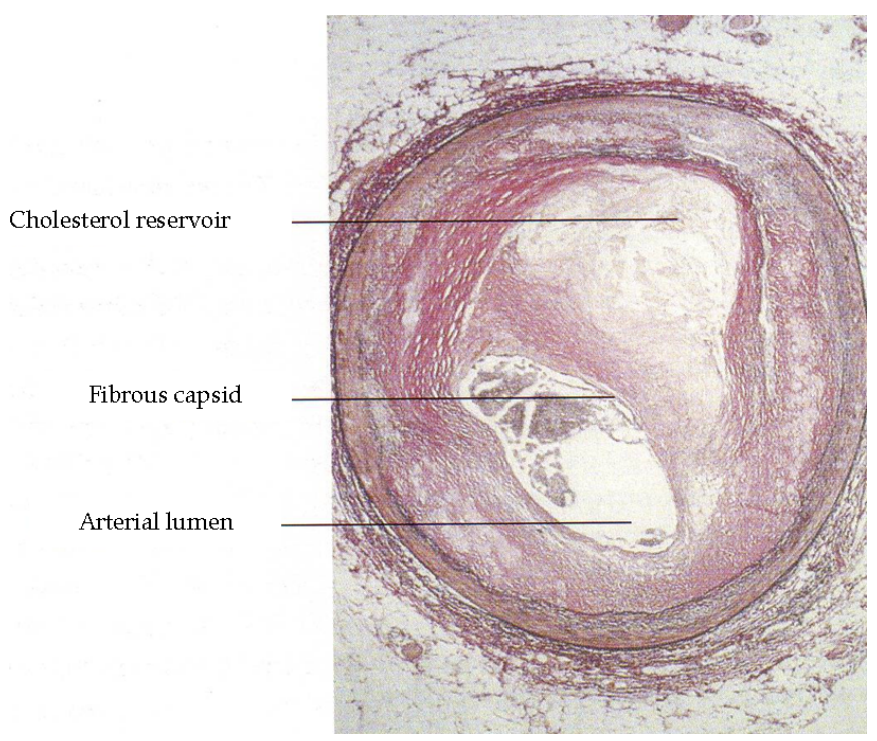

Figure 2. Advanced atheromatous plaque causing arterial lumen occlusion of $70 \%$ (adopted from Durrington \& Sinderman, 2002).

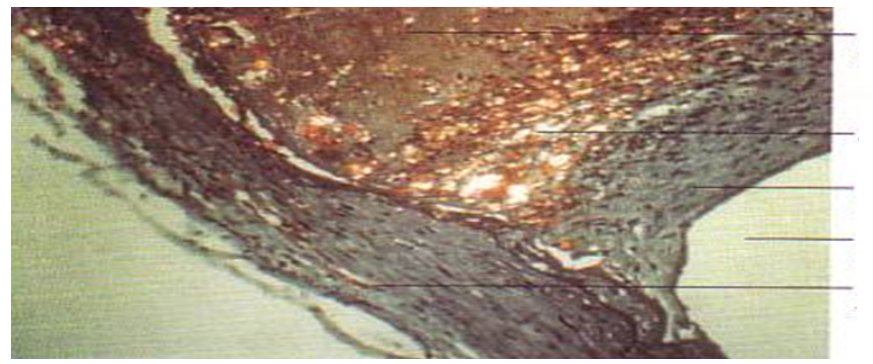

Cholesterol reservoir

Foamy cells

Fibrous capsid

Arterial lumen

Arterial wall

Figure 3. The point of the atheromatous plaque which active enlargement is occurring. Formation of new foamy cells, increased cholesterol uptake and increased instability of the plaque (adopted from Durrington \& Sinderman, 2002). 


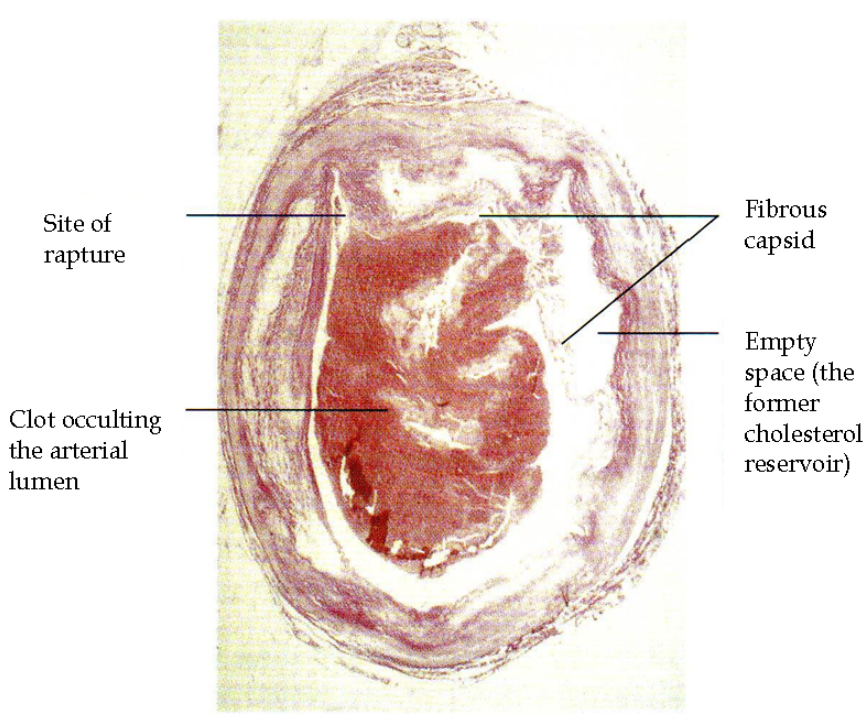

Figure 4. A raptured ahteromatous plaque, in which the cholesterol reservoir has evacuated itself under the fibrous capsid. A clot has in the endothelial surface at the site of rapture is completely occulting the lumen (adopted from Durrington \& Sinderman, 2002).

\subsection{Oxidised LDL}

Oxidized low density lipoprotein LDL (oxLDL) cholesterol in humans is found mainly in two types:

a. conjugated form, attached to the atheromatous plaque and

b. circulating form found in serum.

Oxidized LDL is produced following oxidation of LDL by free radicals and other oxidadive factors, a procedure called oxidative stress. The circulating oxidized LDL is the measurable fraction of oxidized LDL in plasma. Oxidised LDL is a key element of the pathway leading to the formation of the atheromatous plaque and has been extensively studied both as a marker of atheromatosis and as a possible target of therapeutic intervention. Circulating oxLDL is considered a risk marker for atherosclerosis [8] and coronary heart disease (CHD) [8-10]. Increased oxLDL levels in circulation and the vessel wall are associated with endothelial dysfunction [11] in such patients [9,10,12], contributing to atheromatous plaque instability [9].

Oxidative modification of LDL leads to rapid focal accumulation in macrophages [13], which is the first step in atheromatous process. The increased retention time of LDL in the intima offers enhanced probability to be oxidized by free radicals produced by endothelium, smooth muscle cells or macrophages [14]. Oxidized LDL then acts chemotactic for monocytes and smooth muscle cells through binding to scavenger receptors [15], leading to the formation of foam cells. Oxidized LDL is also capable to elicit endothelial dysfunction by altering the 
secretory activity of endothelial cells [15], inhibiting the nitric oxide-mediated vasodilatation through reduction of the expression of endothelial nitric-oxide synthase (eNOS), inducing the expression of adhesion molecules on the endothelium thus mediating the adhesion of monocytes to intima [15], and inducing the expression of inflammatory cytokines [16]. Indeed, oxLDL is a potent inducer of inflammation [17], contributing to the chronic inflammatory process which results to atherosclerosis [18].

\subsection{Statins}

The 3-hydroxy-3-methylglutaryl-coenzyme A reductase inhibitors, or statins, reduce total cholesterol (TC), LDL cholesterol, apolipoprotein B (apoB), and, to a lesser degree, triglycerides and lipoprotein a (Lp-a). Statins also have pleiotropic effects [19], such as the modulation of inflammatory molecules and monocyte maturation and differentiation [19], the suppression of smooth muscle-cells migration and proliferation [19], the reduction of the monocyte adhesion to the endothelium [20], the restoration of the impaired endothelium-dependent vessel wall relaxation [21], and the modification of cell-mediated LDL oxidation [22,23]. All of the above mechanisms contribute to the reversion of atheromatosis. Undeniably, statins reduce the incidence of coronary events and are a cornerstone in the primary and secondary prevention of CHD [24]. Previous studies have detected some efficacy in reducing the circulating oxLDL levels, but whether this effect is due to the reduction of LDL or is an independent, pleiotropic phenomenon remains a matter of controversy $[25,26]$. Furthermore, little is known about the definite clinical benefit of such oxidative marker reduction.

The aim of the present study was to evaluate the efficacy of atorvastatin in reducing stenosis, to investigate the effect on oxLDL and to search for possible associations of oxLDL modification with changes of stenosis in patients managed conservatively and in pre-treated with percutaneous catheter interventional procedures patients with carotid atheromatosis. We hypothesise that atorvastatin therapy will confer remission of oxLDL levels in vivo and this will be associated with significant reduction of carotid artery stenosis.

\section{Patients and methods}

Between January 2005 and February 2008 a total of 100 patients were randomly selected from the lipid clinic and the carotid angioplasty clinic of a large tertiary hospital in Athens for inclusion in the study. Informed consent was obtained from each patient at recruitment according to our institutional policies. Eligible were patients with carotid artery stenosis from various causes and with a range of predisposing factors. Exclusion criteria included: acute cardiovascular disease, severe or unstable angina pectoris, clinically evident cardiac failure, severe arrhythmias, recent surgical procedures, inflammatory diseases, active liver disease or liver impairment, excessive alcohol consumption ( $>4$ units/day) or history of alcohol abuse, known allergic reaction to statins, poorly controlled diabetes mellitus as defined by a haemoglobin A1c (HbA1c) level of $>7 \mathrm{mg} / \mathrm{dl}$, uncontrolled hypertension indicated by systolic blood pressure $(\mathrm{SBP})>140 \mathrm{mmHg}$ and/or diastolic pressure $>85 \mathrm{mmHg}$, history of deep vein throm- 
bosis, bleeding tendency, serum triglycerides $>350 \mathrm{mg} / \mathrm{dl}$, evidence of thyroid dysfunction, use of systemic steroids or other anabolics, pernicious anaemia, impaired vitamin B12 or folate acid levels, abnormal serum urate at baseline, serum creatinine phosphokinase elevation of $>1.5$ fold at baseline, pregnancy or lactation, and end-stage renal disease or dialysis.

Patients were allocated into two groups according to the degree of carotid artery stenosis: those with arterial lumen occlusion of $>70 \%$ in at least one common or internal carotid vessel consisted group A; those with stenosis $<70 \%$ comprised group B. Patients in both groups were naive to statin therapy or if otherwise, a 6-month washout period was allowed before enrolment in the study. Group A underwent percutaneous transluminal carotid angioplasty with stenting by the same interventional cardiologist, prior to the initiation of statin therapy. Those patients were additionally administered clopidrogrel and salicylate. Both groups had to follow an American Heart Association step II diet and were encouraged to exercise.

All patients were placed on atorvastatin once daily at bedtime in individualised doses, tittered to achieve and maintain serum LDL cholesterol levels of $<100 \mathrm{mg} / \mathrm{dl}$ (and ideally $<70 \mathrm{mg} / \mathrm{dl}$, if hypertension, renal impairment, smoking, hyperlipidemia, symptomatic peripheral arterial obstructive disease, or diabetes mellitus were present). The most common doses used to achieve the above levels of LDL ranged between 10 to $40 \mathrm{mg}$, while seldom it was required to administer higher doses such as $60 \mathrm{mg}$ (median atorvastatin dose for the total population = $20 \mathrm{mg}$, range $10-60 \mathrm{mg}$ ). The use of other drugs known to act synergistically with statins causing rhabdomyolysis was prohibited during the study. Adverse events were assessed in every visit in a non-specific manner: every newly reported symptom was documented as possible adverse reaction due to statin therapy and subsequently evaluated by an expert in clinical biochemistry. Adherence to the medication regimen was assessed indirectly by the low LDL levels compared with baseline.

Medical anamnesis, anthropometrics, smoking habits, blood pressure, and laboratory investigations comprising of complete blood count, fasting glucose, $\mathrm{HbA1c}$, liver and kidney biochemistry, detailed lipid profile (TC, LDL cholesterol, high density lipoprotein [HDL] cholesterol, serum triglycerides [TG], apoB, and apolipoprotein A), urate, B12 and folate, thyroid function tests, homocysteine, Lp-a, and oxLDL were obtained at baseline and during follow-up visits, which were arranged at baseline, one, three, and six months; the final assessment was carried out in 12 months. Blood samples were collected after an at least 12hour fast and a light, low-fat meal the night before sample collection was advised. Venous blood samples were collected in standard biochemistry vacutainer tubes. For the analysis of homocysteine and whole blood count, ethylenediaminetetraacetic acid (EDTA) vacutainer was used. Serum for biochemistry analysis was obtained by centrifugation $(4000 \mathrm{~g})$ at $4^{\circ} \mathrm{C}$ for $7 \mathrm{~min}$ and was immediately tested.

Lipid profiles (TC, HDL, TG) were determined using commercially available enzymatic colourimetric methods (Dade Behring, Newark, USA) with a Dade Behring analyser. LDL was calculated with the use of Friedewald's formula as all had TG $<350 \mathrm{mg} / \mathrm{dl}$ [27]. For the measurement of circulating oxLDL, a commercially available kit (Mercodia, Uppsala, Sweden), based on a double antibody (4E6 and mouse monoclonal antiapoB) [28] capture ELISA test, was used. This method primarily detects malondialdehyde LDL (MDA-LDL). The normative 
range (reference range) in our lab was 31-61mU/l. Apolipoprotein A, B and Lp-a were measured using immuno-nephelometry with rabbit antisera (Dade Behring, Newark, USA) in a Dade Behring analyser.

The evaluation of stenosis was conducted by Triplex ultrasonography using an Apogee 800 plus scanner with a $7.5 \mathrm{MHz}$ transducer (ATL Inc., Bothell WA, USA) at baseline and 12 months. The stenosis was calculated in three sections in each common and internal carotid artery, and the final measure was the mean value of the three. The value of stenosis in the most occluded vessel was used in the statistical analysis. Specifically, the internal carotid artery (ICA) and common carotid artery (CCA) bilaterally were evaluated for each patient using coloured and grey Doppler ultrasonography. An effort was made to completely visualize the vessels. Additionally, the pulse wave was estimated with Doppler phasmatometry as well as the blood flow velocity of the two vessels. Results were recorded in a validated form. Stenosis was defined as the presence of visual plaque in coloured or grey Doppler. The degree of stenosis was calculated by measuring the decrease of the lumen diameter and the maximum systolic blood flow velocity. In difficult cases, other parameters were taken into account, such as ICA/CCA max blood flow velocity ratio and the ICA end-diastolic velocity. A degree of stenosis $>70 \%$ was considered as sever and angioplasty was advised. A degree of stenosis between $60-70 \%$ was defined as high, between $50-60 \%$ as moderate and $<50 \%$ as mild. High, moderate and mild stenoses were treated conservatively. The intima media thickness (IMT) and plaque morphology were not studied due to specific lab requirements, not readily available in our institution.

\subsection{Statistical analysis}

Continuous variables were presented as mean values \pm standard deviation, while qualitative variables were presented as absolute and relative frequencies. Normality tests were applied using the Kolmogorov-Smirnov criterion as well as Shapiro-Wilk test. Univariate analysis was initially applied to test the associations of oxLDL with carotid stenosis for each patient group as well as to identify first order correlations with various clinical parameters. Correlations between skewed continuous or discrete variables were evaluated using Spearman's pcoefficient, whereas correlations of normally distributed variables were evaluated by calculating the Pearson's r-coefficient. Comparisons between normally distributed, continuous variables and categorical variables were made using the Student t-test. Analysis of categorical data was carried out with the [chi]2 test or Fischer's exact test when appropriate.

The association of oxLDL with carotid stenosis was also tested through multiple Cox proportional hazard model. The results obtained were presented as Hazard Ratios (HR) and the 95\% Confidence Intervals (CI). A backward elimination procedure was applied to all multivariate models (using $\mathrm{P}<5 \%$ as the threshold for removing a variable from the models). All models were adjusted for age, gender, SBP and TC. Kaplan-Meier curves concerning stenosis over the study period were plotted and Log rank test was performed. All reported P-values were based on two-sided tests and compared to a significance level of 5\%. STATA 8.0 software (Stata Corporation, 2003, Texas, USA) was used for the analysis. 


\section{Results}

\subsection{Patients' characteristics}

A total of 612 patients were evaluated, of which 123 fulfilled the eligibility criteria; finally, 100 had complete data to enter the analysis, 76 males and 24 females, median age 68 years (range $45-81$ ). Diabetes mellitus was recorded in 26 of the 100 patients and hypertension in 66 . Twenty patients had metabolic syndrome according to the national cholesterol education programmeadult treatment panel III (NCEP-ATP III) criteria [29]. Active smoking (defined as current of discontinued as far back as 5 years) was reported by 58 patients. Mean atorvastatin dose at baseline was $24.31 \pm 11.49 \mathrm{mg}$ for group $\mathrm{A}$ and $20.62 \pm 10.39 \mathrm{mg}$ for group $\mathrm{B}(\mathrm{p}=0.1)$. By the end of the study period, the respective mean values were significantly increased to $30.45 \pm 16.27 \mathrm{mg}$ for group A ( $\mathrm{p}=0.044)$ and $28.75 \pm 17.57 \mathrm{mg}$ for group $\mathrm{B}(\mathrm{p}=0.007)$.

Each of the study group (A and B) comprised 50 patients. The two groups were comparable with regard of their baseline characteristics (table 1).

\subsection{Lipid profile and oxidised LDL}

Mean serum TC, LDL-cholesterol, TG, Lp-a, homocysteine, HDL-cholesterol, and oxLDL were significantly reduced at 12 months compared to baseline (table 2). Specifically, mean oxLDL dropped from $62.26 \pm 22.03 \mathrm{mU} / 1$ to $44.49 \pm 21.75$ ( $\mathrm{p}<0.001$ ). A marked decrease was noticed during the first 6 months and a plateau thereafter (Figure 5).

\begin{tabular}{lllll}
\hline Characteristic & Total & Group A & Group B & p value \\
\hline males / females & $72 / 28$ & $36 / 14$ & $36 / 14$ & \\
\hline mean age in years \pm SD & $67.57 \pm 7.15$ & $68.46 \pm 5.71$ & $66.68 \pm 8.31$ & 0.21 \\
\hline number of pts with DM (percentage) & $37(37 \%)$ & $18(36 \%)$ & $19(38 \%)$ & 0.83 \\
\hline number of pts with HTN (percentage) & $67(67 \%)$ & $36(72 \%)$ & $31(62 \%)$ & 0.29 \\
\hline number of smokers (percentage) & $54(54 \%)$ & $29(54 \%)$ & $25(46 \%)$ & 0.33 \\
\hline number of pts with CAD (percentage) & $51(51 \%)$ & $24(47 \%)$ & $27(53 \%)$ & 0.55 \\
\hline mean \pm SD total cholesterol $(\mathrm{mg} / \mathrm{dl})$ & $232.23 \pm 47.8$ & $235.24 \pm 49.2$ & $229.22 \pm 46.7$ & 0.53 \\
\hline mean \pm SD LDL cholesterol $(\mathrm{mg} / \mathrm{dl})$ & $151.27 \pm 41.7$ & $154.16 \pm 42.8$ & $148.84 \pm 40.9$ & 0.52 \\
\hline mean \pm SD HDL cholesterol $(\mathrm{mg} / \mathrm{dl})$ & $51.97 \pm 12.7$ & $52.12 \pm 12.1$ & $51.82 \pm 13.4$ & 0.9 \\
\hline mean \pm SD triglycerides $(\mathrm{mg} / \mathrm{dl})$ & $145.59 \pm 73.1$ & $146.04 \pm 73.2$ & $145.14 \pm 73.7$ & 0.95 \\
\hline mean \pm SD oxidized LDL $(\mathrm{mU} / \mathrm{l})$ & $64.66 \pm 24.8$ & $65.8 \pm 25.3$ & $63.53 \pm 24.5$ & 0.65 \\
\hline mean \pm SD homocysteine $(\mathrm{mU} / \mathrm{l})$ & $13.99 \pm 4.8$ & $13.5 \pm 4.6$ & $14.47 \pm 5.1$ & 0.32 \\
\hline
\end{tabular}

Pts: patients, DM: diabetes mellitus, HTN: arterial hypertension, MS: metabolic syndrome, SD: standard deviation, LDL: low density lipoprotein, HDL: high density lipoprotein, CAD: coronary artery disease

Table 1. Study population baseline characteristics 
A significant correlation between LDL and oxLDL levels was detected (Pearson's correlation coefficient $\mathrm{r}=0.7, \mathrm{p}<0.01$ ) (Figure 6). Similar correlation was found between oxLDL and apoB levels $(\mathrm{r}=0.65, \mathrm{p}<0.001)$, while no significant correlation was shown with Lp-a.

Between smokers mean oxidized LDL was reduced from $60.68 \pm 24.09 \mathrm{mU} / \mathrm{l}$ at baseline to $45.84 \pm 24.89 \mathrm{mU} / \mathrm{l}$ at the end of study period (difference $14.84 \mathrm{mU} / \mathrm{l}, \mathrm{p}=0.0036$ ). Similarly, between non-smokers it was reduced from $69.33 \pm 25.11$ to $40.36 \pm 5.6$ (difference 28.97, $\mathrm{p}<0.001$ ). Non-smokers had approximately double decline of oxidized LDL levels compared to smokers. Carotid artery stenosis was reduced between smokers from $29.68 \pm 25.59 \%$ at baseline to $23.06 \pm 21.71 \%$ at 12 months $(\mathrm{p}=0.002)$. Non-smokers also presented significant reduction of stenosis during the study period $24.67 \pm 26.22 \%$ vs $20 \pm 21.45 \%$, p $=0.004$ ). Non-smokers and smokers had similar decline of carotid stenosis in 12 months (6.61\% vs $4.67 \%$, Table 3$)$.

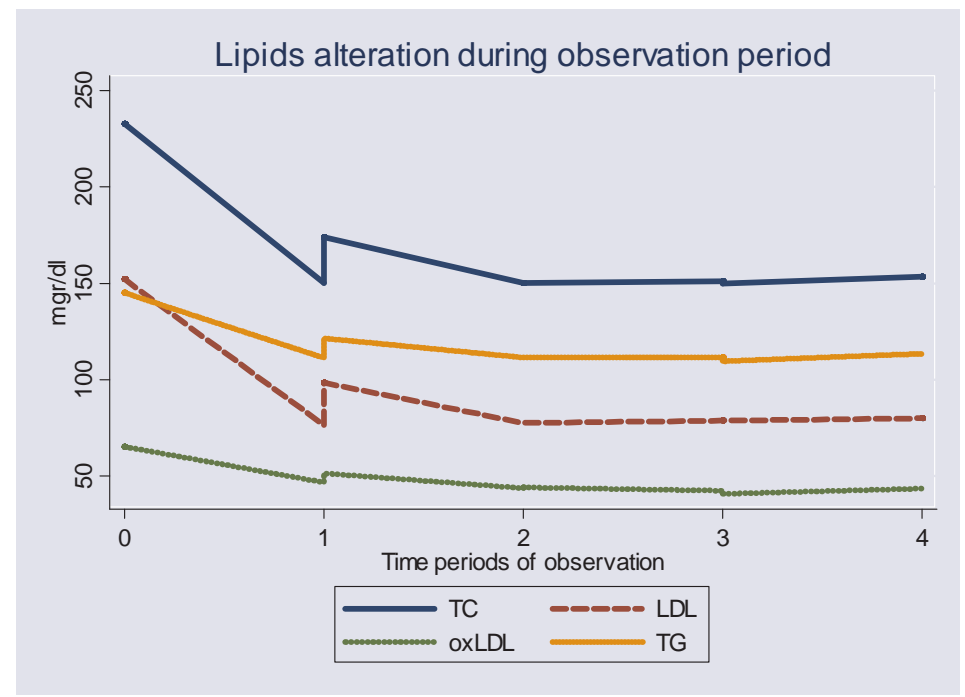

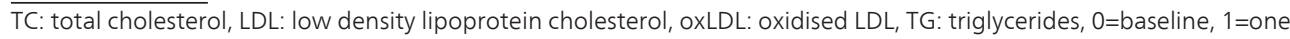
month, 2=three months, $3=$ six months, 4=twelve months.

Figure 5. Time curve of change of total cholesterol, LDL cholesterol, triglycerides and oxidised LDL levels during the observation period.

In further analysis, the group of smokers was subdivided to mild ( $\leq 5$ cigarettes/day), moderate (5 - 15 cigarettes/day) and heavy ( $\geq 15$ cigarettes/day) smokers. The statistical significant reduction of oxidized LDL levels and degree of carotid stenosis was apparent in the subgroup of mild smokers (oxidized LDL at baseline $48.24 \pm 8.74 \mathrm{mU} / \mathrm{l}$ vs $41.54 \pm 9 \mathrm{mU} / 1$ at $12 \mathrm{months}, \mathrm{p}=$ 0.027 and stenosis at baseline $27.63 \pm 25.68 \%$ vs $23.42 \pm 21.74 \%$ at 12 months, $p=0.009$ ), while it was not apparent in the subgroups of moderate and heavy smokers (oxidized LDL at baseline $86.82 \pm 37.7 \mathrm{mU} / \mathrm{l}$ vs $42.92 \pm 10.77 \mathrm{mU} / 1$ at 12 months, $\mathrm{p}=0.077$ and stenosis at baseline $34 \pm 31.9 \%$ vs $22 \pm 24.9 \%$ at 12 months, $\mathrm{p}=0.186$, for moderate smokers; respective values for oxidized LDL were $66.29 \pm 15.88 \mathrm{mU} / \mathrm{l}$ vs $34.81 \pm 5.48 \mathrm{mU} / \mathrm{l}, \mathrm{p}=0.06$ and for stenosis $32.14 \pm 24.13 \%$ vs 
$22.86 \pm 22.8 \%, p=0.174$, for heavy smokers). The above described effect of smoking was taken into consideration during Cox-regression analysis.

\begin{tabular}{|c|c|c|c|}
\hline Investigations & Total & Group A & Group B \\
\hline total cholesterol (mg/dl) baseline & $232.23 \pm 47.8$ & $235.24 \pm 49.1$ & $229.22 \pm 46.7$ \\
\hline total cholesterol (mg/dl) 12months & $153.36 \pm 17.2$ & $154.24 \pm 16.9$ & $152.48 \pm 17.7$ \\
\hline p value & $<0.0001$ & $<0.0001$ & $<0.0001$ \\
\hline LDL cholesterol (mg/dl) baseline & $151.5 \pm 41.7$ & $154.16 \pm 42.8$ & $148.84 \pm 40.9$ \\
\hline LDL cholesterol (mg/dl) 12months & $79.75 \pm 12.7$ & $79.54 \pm 13.2$ & $79.96 \pm 12.3$ \\
\hline $\mathrm{p}$ value & $<0.0001$ & $<0.0001$ & $<0.0001$ \\
\hline triglycerides (mg/dl) baseline & $145.59 \pm 73.1$ & $146.04 \pm 73.2$ & $145.14 \pm 73.7$ \\
\hline triglycerides (mg/dl) 12months & $111 \pm 53.1$ & $112.1 \pm 54.7$ & $109.9 \pm 51.96$ \\
\hline$p$ value & 0.0002 & 0.01 & 0.0069 \\
\hline oxidized LDL (mU/l) baseline & $64.67 \pm 24.8$ & $65.8 \pm 25.3$ & $63.53 \pm 24.6$ \\
\hline oxidized LDL (mU/l) 12months & $43.38 \pm 18.9$ & $42.16 \pm 17.6$ & $44.65 \pm 26.1$ \\
\hline p value & $<0.0001$ & $<0.0001$ & 0.0007 \\
\hline HDL cholesterol (mg/dl) baseline & $51.97 \pm 12.7$ & $52.12 \pm 12.1$ & $51.82 \pm 13.4$ \\
\hline HDL cholesterol (mg/dl) 12months & $51.32 \pm 15.5$ & $52.22 \pm 16.3$ & $50.42 \pm 14.8$ \\
\hline$p$ value & 0.74 & 0.97 & 0.62 \\
\hline homocysteine (mg/dl) baseline & $13.99 \pm 4.8$ & $13.5 \pm 4.6$ & $14.48 \pm 5.1$ \\
\hline homocysteine (mg/dl) 12months & $11.89 \pm 3.5$ & $11.88 \pm 3.8$ & $11.9 \pm 3.4$ \\
\hline$p$ value & 0.0006 & 0.057 & 0.0036 \\
\hline apolipoprotein A (mg/dl) baseline & $156.57 \pm 26.7$ & $156.46 \pm 27.3$ & $156.68 \pm 26.4$ \\
\hline apolipoprotein A (mg/dl) 12months & $160.35 \pm 25.3$ & $162.02 \pm 23.7$ & $158.68 \pm 27.1$ \\
\hline$p$ value & 0.3 & 0.28 & 0.7 \\
\hline apolipoprotein B (mg/dl) baseline & $129.95 \pm 31.3$ & $131.84 \pm 31.4$ & $128.05 \pm 31.4$ \\
\hline apolipoprotein B (mg/dl) 12months & $77.1 \pm 11.8$ & $77.58 \pm 13.1$ & $76.62 \pm 10.47$ \\
\hline$p$ value & $<0.0001$ & $<0.0001$ & $<0.0001$ \\
\hline lipoprotein a [Lp(a)] (mg/dl) baseline & $25.08 \pm 23.8$ & $25.67 \pm 24.1$ & $24.47 \pm 23.8$ \\
\hline lipoprotein a [Lp(a)] (mg/dl) 12months & $27.72 \pm 29.1$ & $29.42 \pm 29.8$ & $26.01 \pm 28.7$ \\
\hline$p$ value & 0.48 & 0.49 & 0.77 \\
\hline
\end{tabular}

LDL: Iow density lipoprotein, HDL: high density lipoprotein

Table 2. Comparison of mean \pm standard deviation and respective $p$ values of measured laboratory investigations at baseline and 12 months, in the total population, and the two groups. 


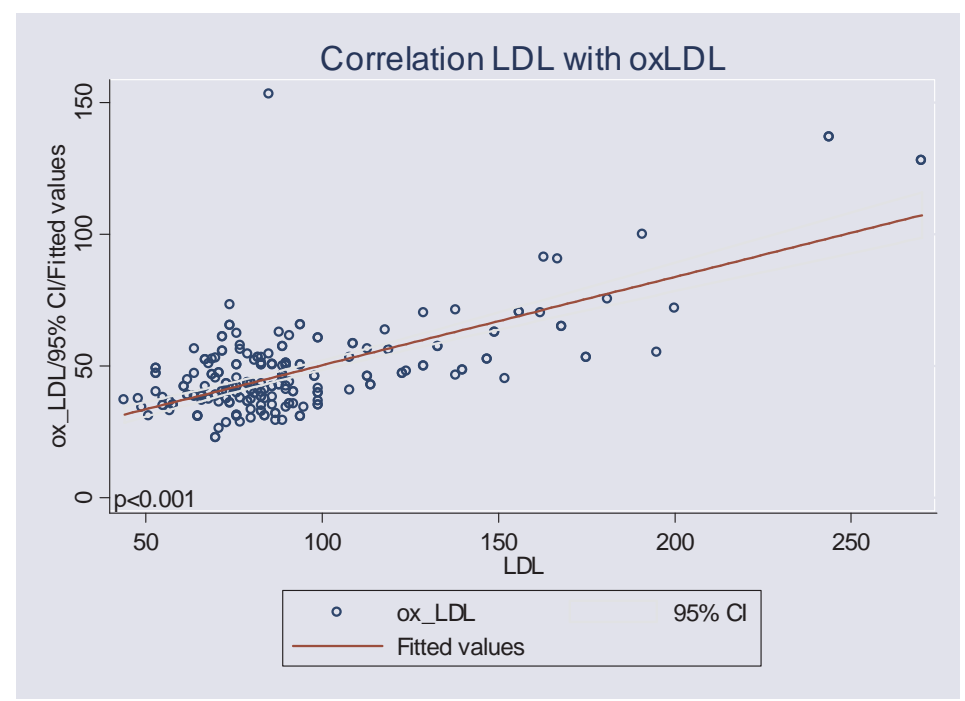

LDL: low density lipoprotein cholesterol, oxLDL: oxidised LDL, Cl: confidence intervals.

Figure 6. Correlation of low density lipoprotein (LDL) with oxidised LDL (oxLDL) levels at baseline (Pearson's correlation coefficient $r=0.7, p<0.001$ )

\begin{tabular}{|c|c|c|c|c|}
\hline & Smokers & $P$ value & Non Smokers & P value \\
\hline $\begin{array}{l}\text { ox LDL }(\mathrm{mg} / \mathrm{dl}) \\
\text { baseline } \\
12 \text { months } \\
\text { difference }\end{array}$ & $\begin{array}{c}60.68 \pm 24.09 \\
45.48 \pm 24.89 \\
14.84\end{array}$ & 0.0036 & $\begin{array}{c}69.33 \pm 25.11 \\
40.36 \pm 5.6 \\
28.97\end{array}$ & 0.001 \\
\hline $\begin{array}{l}\text { stenosis (\%) } \\
\text { baseline } \\
12 \text { months } \\
\text { difference }\end{array}$ & $\begin{array}{c}29.68 \pm 25.59 \\
23.06 \pm 21.71 \\
6.61\end{array}$ & 0.002 & $\begin{array}{c}24.67 \pm 26.22 \\
20 \pm 21.45 \\
4.67\end{array}$ & 0.004 \\
\hline $\begin{array}{l}\text { Correlation of oxLDL change } \\
\text { with stenosis change in } 12 \\
\text { months }\end{array}$ & $\begin{array}{l}\text { Pearson's } \\
r=0.412\end{array}$ & 0.021 & $\begin{array}{l}\text { Pearson's } \\
r=0.198\end{array}$ & 0.03 \\
\hline
\end{tabular}

Table 3. Comparison of mean oxidized LDL values and degree of carotid stenosis change during the 1 year follow-up period, between smokers and non-smokers.

Within group B, the subgroup of patients with high degree of stenosis ( $>60 \%)$ had oxLDL $63.47 \pm 19.18 \mathrm{mU} / \mathrm{l}$ at baseline, while those with moderate and mild degree of stenosis $(<60 \%)$ had $40.32 \pm 20.72 \mathrm{mU} / 1(\mathrm{p}<0.001)$. Corresponding values at 12 -months were $33.18 \pm 17.78$ and 
$38.81 \pm 29.02$, representing a marked decline for patients with $>60 \%$ initial stenosis and a far less decline for patients with $<60 \%$ initial stenosis; yet the differences were not significant (table 4 ).

\begin{tabular}{cccc}
\hline & Stenosis $>60<70 \%$ & Stenosis $<60 \%$ & P value \\
\hline $\begin{array}{c}\text { Baseline } \\
\text { Mean oxidized LDL }\end{array}$ & $63.47 \pm 19.18 \mathrm{mU} / \mathrm{l}$ & $40.32 \pm 20.72 \mathrm{mU} / \mathrm{l}$ & $<0.001$ \\
\hline 12 months Mean oxidized LDL & $33.18 \pm 17.78 \mathrm{mU} / \mathrm{l}$ & $38.81 \pm 29.02 \mathrm{mU} / \mathrm{l}$ & NS \\
\hline
\end{tabular}

Table 4. Comparison of mean oxidized LDL levels at baseline and 12 months within patients of group B $(n=50)$, according to degree of stenosis at enrollment.

\subsection{Anthropometrics}

Body mass index (BMI), weight, waist circumference and waist:hip ratio did not change significantly during the study period.

\subsection{Carotid stenosis}

Patients in group A had null stenosis at recruitment due to prior angioplasty with stenting. At the end of the 12-month statin therapy, no case of clinically important restenosis $(>70 \%)$ was reported in this group (as restenosis was defined any increase of the carotid lumen diameter $>5 \%$ ). Patients in group B had mean percentage of stenosis at baseline $47.6 \pm 13.2 \%$, which was significantly reduced following 12-month statin therapy $(37.7 \pm 15.7 \%$, $\mathrm{p}<0.001)$ (Table 5).

\begin{tabular}{llll}
\hline & baseline & 12 months & p value \\
\hline Mean \% carotid stenosis \pm standard deviation & $47,6 \pm 13,2$ & $37,7 \pm 15,7$ & 0,001 \\
\hline
\end{tabular}

Table 5. Change of the percentage of carotid artery stenosis between baseline and 12 months for patients in group B.

\subsection{Association of stenosis with oxidised LDL}

Group B patients in the highest quartile of oxLDL values had a 12-month risk ratio for restenosis of $1.025,95 \% \mathrm{CI}=1.006-1.044, \mathrm{p}=0.0083$ (figure 7 ). After adjusting for gender, age, smoking, SBP, TC, and LDL levels, these patients demonstrated a HR for restenosis of 4.319 compared with those in the lowest quartile $(\mathrm{p}<0.001$, figure 7$)$. This means that an increase of oxidized LDL by one unit increases the degree of carotid stenosis by $2.5 \%$, for patients in group B. A weak but significant correlation was detected between oxLDL levels and the degree of carotid artery stenosis $(\mathrm{r}=0.17, \mathrm{p}=0.018)$. Similar correlation was found between LDL cholesterol levels and carotid stenosis $(\mathrm{r}=0.18, \mathrm{p}=0.0085)$. The strength of Pearson's correlation of mean oxidised LDL change with degree of carotid stenosis change during the 12-month period was greater for smokers compared to non-smokers (table 3). 


\subsection{The effect of LDL levels}

Patients in group B who achieved LDL levels $<70 \mathrm{mg} / \mathrm{dl}$ during the observation period had a greater $(28.08 \pm 28 \%$ vs $22.31 \pm 22.7 \%$, difference $5.77 \%, \mathrm{p}=0.06)$ reduction of carotid stenosis compared to those with LDL levels between 70 and $100 \mathrm{mg} / \mathrm{dl}(26.98 \pm 25.3 \%$ vs $21.35 \pm 21.3 \%$, difference $5.63 \%, \mathrm{p}<0.001$ ), but this difference was not statistically significant. Thus, in conservatively treated group B, further reduction of LDL than the limit of $100 \mathrm{mg} / \mathrm{dl}$ was not associated with additional improvement of stenosis.

\section{Discussion}

This study demonstrates that atorvastatin administered in indivudualised doses, tittered to maintain serum LDL cholesterol levels $<100 \mathrm{mg} / \mathrm{dl}$, significantly decreased lipid profile and oxLDL, reduced carotid artery stenosis in patients managed conservatively and prevented restenosis in patients with prior angioplasty. Oxidised LDL in this study correlated positively with the degree of carotid artery stenosis; it was also shown by multivariate analysis that oxLDL represented an independent risk factor for restenosis. To our knowledge this is the first prospective study with a long observation period of 12 months to report such a clear, significant reduction of oxLDL levels following atorvastatin therapy for carotid atheromatosis of various causes and to report an association of the degree of oxLDL reduction with remission of carotid stenosis. It is also of major importance that this robust, long-standing decline of oxLDL was achieved with doses of atorvastatin used in everyday clinical practice. Interestingly, this beneficial effect was completed in the first six months, while practically no further reduction was noticed past this time point.

The mechanism by which statins modulate oxLDL levels has been controversial in the literature. Moreover, the association of oxLDL level modification with improvement of carotid atheromatosis and clinical outcome is not unequivocally established by large, double-blinded, randomised trials. Under this perspective, the present observational study provides reasonable evidence that reducing oxLDL may independently improve carotid stenosis.

Carotid intima media thickness (IMT) is a validated measure of carotid atherosclerosis. It is well established that carotid atherosclerosis, serves as an independent surrogate marker for CHD [30] and CVD [31]. Nevertheless, in the present study it was preferred to estimate the degree of carotid stenosis with a more direct approach, because this is more readily available in most hospital settings and because there is an obvious relation with clinical symptoms and signs. Besides, it represents a reliable method with sufficient reproducibility and it is practically the method of choice when evaluated patients candidate for endarterectomy or angioplasty. Evaluating carotid stenosis in turn, is an established method for estimating coronary risk [30] and cardiovascular risk [31]. Other parameters of vessel wall function, such as IMT and plaque morphology, even if clearly associated with cardiovascular risk in the literature, require well equipped laboratory and are not readily available in our hospital. Future research on the field should, ideally, comprise such measurements. 


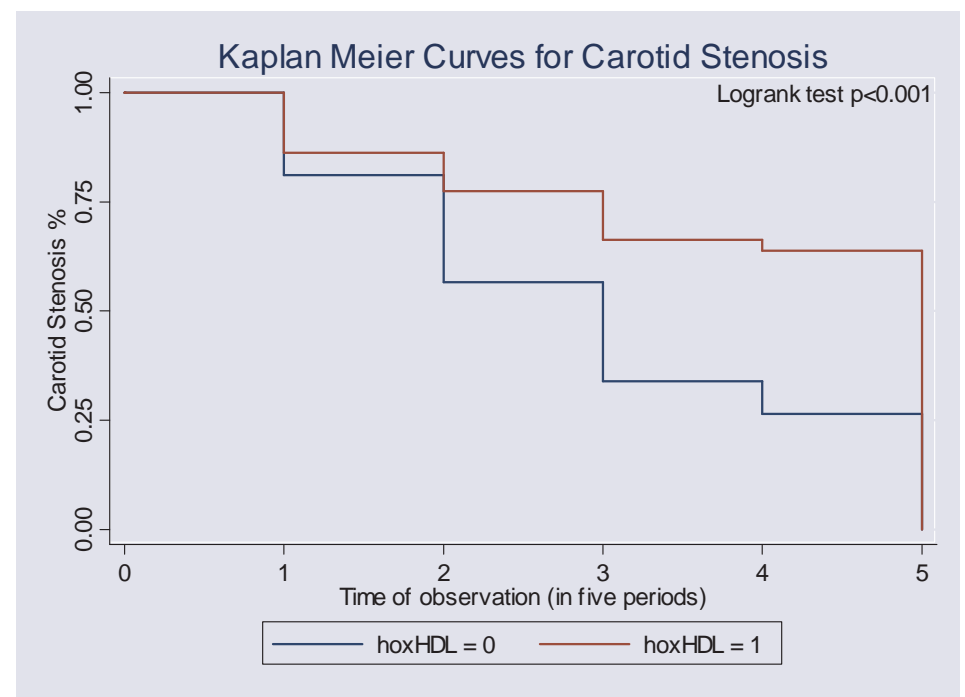

hoxLDL=0: low quartile of oxidised $L D L$ levels, hoxLDL=1: high quartile of oxidised $L D L$ levels, $0=$ baseline, $1=0$ ene month, 2=three months, $3=$ six months, 4=twelve months.

Figure 7. Kaplan Meier survival analysis for the estimation of the risk ratio for restenosis according to the levels of oxidised LDL (oxLDL). With red line those with oxLDL levels in the highest quartile of the values. With blue line those with oxLDL levels in the lowest quartile of the measurements (risk ratio 1.025, logrank test $p<0.001$ ).

Oxidised LDL has long been recognized as a risk factor for carotid atherosclerosis in asymptomatic men [32] and has also been linked with CVD [33]. Oxidized LDL levels [34], autoantibodies against epitopes of oxLDL [34] and oxLDL:LDL ratio [30] are independently associated with increased risk for coronary atheromatosis and ischemic heart disease. Increased levels of oxLDL [9] and MDA-LDL [10] in such cases are related to plaque instability. On the other hand, it has been reported that oxLDL is weakly associated with carotid IMT, but not with carotid plaque occurrence [35]. Oxidised LDL impairs endothelium relaxation [36] by inhibition of the expression of eNOS and of the transport pathways of nitric oxide (NO) from the endothelial cell, reduces the responsiveness of smooth muscle cell to NO [37], inhibits the NO-mediated vasodilation [16,36,38], induces the expression of adhesion molecules [39], acts directly chemotactic to circulating monocytes [16], stimulates endothelial cells to produce monocyte chemoattractant protein-1 (MCP-1) [40], facilitates monocyte adhesion to intima [41], exhibits cytotoxic properties against endothelial cells [16], and induces the expression of inflammatory molecules [16]. All of the above contribute directly to dysfunction of the endothelium [13] and foam cell formation, which is the first step in the development of fatty streaks [18], the first visible step of atherosclerosis. These effects are mediated by preferential binding of oxLDL with type A scavenger receptors (SRA, SRA-II and CD36) on subendothelial resident macrophages and smooth muscle cells [42] and lectin-like oxLDL receptor-1 (LOX-1) on endothelial cells [43] rather than the typical LDL receptor, resulting in an unrestricted uptake of cholesterol. 
Statins reduce the incidence of cardiovascular events, an effect attributable to their hypocholesterolemic properties [44]. However, the extent of clinical benefit and accumulating laboratory evidence suggest additional mechanisms of action, the so-called pleiotropic effects [19]. The most important among such effects are the suppression of smooth muscle cell migration and proliferation [45], the reduction of monocyte adhesion to the vascular endothelium [20], the improvement of endothelial function [21], the inhibition of cell-mediated LDL oxidation $[22,23]$, the immuno-modulation of monocyte maturation and differentiation, and the modification of production of inflammatory cytokines [46].

Atorvastatin suppresses cellular uptake of oxLDL from differentiating monocytes by reducing the expression of LOX-1 and scavenger receptors [47] and accelerates the LDL-receptormediated removal of the non oxidized LDL particles [48]. Hydroxymetabolites of atorvastatin protect the LDL against oxidation [31]. The antioxidant potency of atorvastatin metabolites has been confirmed by the reduction of IgG antibodies against LDL, a marker well-associated with CHD [23]. It has even been reported that these active atorvastatin metabolites may have greater anti-atherosclerotic effects than other statin molecules [49].

In acute coronary syndromes, atorvastatin therapy was linked to modulation of short- and long-term immune response towards LDL due to inhibition of lipoprotein-associated phospholipase A2 (Lp-LPA2) enzyme [34]. The apparent benefit from statin therapy after acute coronary events may also be attributed to the stabilization of the plaque and removal of oxLDL from the vessel wall [50]. Increased mobilization of oxidized phospholipids from the vessel wall, transient binding with apoB-100 particles and clearance from the circulation may be the possible underlying mechanism. Under this perspective the increase in oxLDL:apoB ratio detected with atorvastatin therapy might represent a marker of oxLDL efflux from the vessel wall. Removal of oxLDL contributes to improved endothelial function as oxLDL is highly immunogenic and vasoconstrictive. In our study there was no significant change in oxLDL:apoB ratio. Atorvastatin also inhibits the oxLDL-mediated LOX-1 expression by endothelial cells, the uptake of oxLDL in endothelium and the oxLDL-mediated reduction of protein kinase $\mathrm{B}$ (PKB) phosphorylation [24]. The activation of $\mathrm{PKB}$ is critical for the expression of eNOS, which promotes vessel relaxation. However, a meta-analysis provided no clear evidence that statin therapy have a favourable effect on oxLDL [51].

In STAT trial [52] the antibodies against oxLDL were equally decreased with both aggressive and conventional lipid-lowering therapy. This indicates that the statin-related reduction of oxLDL is not a dose-dependent phenomenon, a finding which is in agreement with our results. It might therefore represent a pleiotropic effect, independent -at least partially- from the hypocholesterolemic action. A study by Orem et al detected a significant decrease of autoantibodies against oxLDL with low doses of atorvastatin (10mg) [53], similar to doses used in our study. In statin exposed patients, intensification of the regimen offers no additional benefit and only those with LDL $>125 \mathrm{mg} / \mathrm{dl}$ benefited from a more aggressive statin therapy [52]. Statins have a dose-related response with regard to clinical outcome, but this dose-related response has not been confirmed with regard to oxidative stress [54]. This might alternatively be explained by the hypothesis that statins achieve their uttermost benefit on oxLDL after a certain time point [52], after which further continuation of treatment serves only the purpose of maintenance. 
Atorvastatin has been shown to reduce small dense LDL subfractions, remnant-like particles cholesterol and oxLDL, and improve endothelial function, after just few weeks of therapy $[55,56]$. Such time-related effect has not been fully elucidated, but may possibly account for our finding that in the first six months there was an accelerated decline of oxLDL levels followed by a milder reduction rate thereafter.

Additional pleiotropic effects of statins have been reported in the literature and might account for the observed beneficial effects in the current study. Lysophosphatidylcholine is elevated during LDL oxidation and is responsible for some of the biological effects of oxLDL. Atorvastatin alters the ability of oxLDL to impair the endothelium relaxation, by modulating the hydrolysis of phosphatidylcholine to lysophosphatidylcholine when LDL is being oxidized [57]. Statins remove predominately "aged LDL" from plasma, which is more prone to oxidation [53], through stimulation of hepatic LDL receptor activity and inhibition of very-low density lipoprotein (VLDL) and LDL production by the liver cells [53]. Statins also reduce oxygen species generation [54]. Atorvastatin promotes adipocyte uptake of oxLDL in rabbits by increasing the expression of CD36 and peroxisome proliferators-activated receptor $\gamma$ (PPAR $\gamma$ ) in adipocytes [58]. The increased expression of such receptors by adipocytes results to internalization of oxLDL and clearance from plasma, converting adipocytes to an oxLDLbuffering pool [58]. Reduction of oxLDL in patients with CHD with atorvastatin 10mg parallel with an increase of adiponectin, which has anti-atherogenic [55], anti-inflammatory and antidiabetic [55] properties through reduction of insulin resistance [55]. The CARDS study reported a significant degree of preventive activity of atorvastatin against myocardial infarction in eucholesterolemic diabetic patients, conceivably attributed to such improvement of insulin sensitivity [55]. Statins also diminish the expression of CD40 and CD40 ligand in vascular cells, smooth muscle cells and macrophages, which are promoted by oxLDL and are considered proatherogenic [59]. Other anti-inflammatory pathways include reduction of Creactive protein [60], chemokines, major histocompatibility complex II molecules, matrixdegrading enzymes, and procoagulant tissue factor [59]. Atorvastatin reverses the oxLDLmediated inhibition of vascular endothelial growth factor-induced endothelial progenitor cell differentiation via the phosphatidylinositol 3 kinase/Akt pathway [61], which restores the oxLDL-related inhibition of mature endothelial cells migration [61]. This could improve neovascularization and collateral vessel formation in response to tissue ischemia. Atorvastatin also suppresses platelet activity [62] by reducing the expression of CD36 and LOX-1, which are present in platelets [43,62], thus inhibiting the oxLDL-mediated platelet hyperactivity [62]. Statins reduce the oxLDL-derived expression of adhesion molecules (E- and P-selectins, vascular cell adhesion molecule 1 [VCAM-1] and intercellular adhesion molecule 1 [ICAM-1]) in human coronary artery endothelial cells [15], through up-regulation of eNOS expression [15], which regulates the expression of adhesion molecules in endothelial cells [15]. Statins also diminish the oxLDL-mediated activation of nuclear factor- $\kappa \mathrm{B}(\mathrm{NF}-\kappa \mathrm{B})$ [15], which regulates the transcription of adhesion molecule genes [33]. In diabetic patients with dyslipidemia atorvastatin reduced CVD and markers of inflammation, adhesion and oxidation, such as CRP, soluble ICAM-1, soluble VCAM-1, E-selectin, matrix metalloproteinase 9, secretory phospholipase A2 (sPLA2), and oxLDL, the latter by 38,4\% [60]. Moreover, the change of oxLDL levels correlated with the change of sICAM-1 and E-selectin levels, suggesting that statins could 
possibly counteract the oxLDL-associated increase of NF- $\kappa \mathrm{B}$, and therefore, the production of such cell adhesion molecules [60]. Statins also enhance scavenger receptor expression in macrophages [60], and increase plaque stability via reduction of metalloproteinases [60].

The reduction of oxidised LDL and of carotid stenosis in our study was relevant for both, smokers and non-smokers. However, during subgroup analysis showed that the beneficial effect of statin use concerns mostly the subgroup of mild smokers, while no such effect was noticed for moderate and heavy smokers. How smoking may diminish the beneficial effect of statins on oxidized LDL and carotid stenosis is not yet clarified in the literature. A reasonable assumption might be that, since smoking increases the oxidative stress, it contributes to enhanced LDL oxidation [63]. Moreover, studies in animal models, have demonstrated that smoking alters the immunologic response to oxidized LDL by reducing the production of antibodies against these molecules, i.e. causing a kind of immune suppression regarding the response to oxidized LDL. Thus, it has been shown to increase carotid IMT [64].

The Mercodia oxLDL detects the MDA-modified apoB [28]. It has been proposed that oxLDL looses its predictive value for CVD when adjustment for apoB level is performed [54]. In several studies though, a significant reduction of Mercodia oxLDL with atorvastatin 10mg was still detected even after adjustment for apoB, $[10,31,54]$, while in other studies no adjustment for LDL or apoB levels was made $[54,65]$. In our study the oxLDL:apoB ratio remained unchanged, but in the multivariate analysis the reduction of oxLDL was still significant after adjustment for apoB and LDL levels.

In patients with familial hypercholesterolemia a lack of association between oxLDL and IMT was reported at baseline, however two years therapy with atorvastatin $80 \mathrm{mg}$ was associated with regression of carotid IMT [66]. The LDL subfraction profile and autoantibodies against oxLDL remained unchanged. Nevertheless, the rate of oxidation and the amount of dienes formed decreased and this was linked to lessening of atherosclerosis. In our study the reduction of carotid stenosis was associated with decreased oxLDL levels. Besides, the unchanged oxLDL autoantibodies levels do not preclude the reduction of oxLDL, as was indicated in another study involving dialysis patients, where atorvastatin therapy reduced plasma oxLDL, whereas oxLDL autoantibodies did not changed significantly [67].

Disadvantages of the study were the relatively small size, the lack of a control group comprising of patients with carotid stenosis not on statin therapy, which would be unethical, the fact that researchers were not blinded to the patients' status, the lack of randomization of the dose-schedules and the use of only one method to detect oxLDL.

\section{Conclusion}

This prospective, cross-sectional study with such a long observation period provided enough evidence to postulate a favourable effect of low-dose atorvastatin therapy on oxLDL, which was additionally associated with improvement of stenosis in patients with carotid atheromatosis. We thus, assume that oxidised LDL may represent a far more sensitive risk factor for 
carotid stenosis, than LDL itself or apoB. Further studying is required to confirm such findings and to establish a clear clinical and pathophsiologic link between oxLDL and carotid stenosis.

\section{Acknowledgements}

The authors wish to acknowledge Dr. Antonios Polydorou for performing the catheterizations and stenting of the cartotid arteries in the group of patients that underwent intervention prior entering the study. We also thank him for allowing us access to the records of the angioplasty lab. Finally we are grateful for valuable advice and reviewing this manuscript before publishing.

We also wish to acknowledge Dr. Ioannis Dermitzakis for the critical contribution in evaluating the degree of stenosis of our patient population, as director of the ultrasonography laboratory in our institution. Without his help and valuable assistance this whole project would not have been completed.

The authors finally acknowledge Mrs. Anna Zervou for carrying out the biochemical laboratory measurements with diligence and accuracy, overlooking tiredness, physical and emotional strain. We thank her for her personal commitment in the success of this research.

\section{Author details}

Elias Skopelitis, Dimitrios Levisianou, Helen Lydataki and Sofoklis Kougialis

General Hospital of Nikaia and Piraeus, Athens, Greece

\section{References}

[1] Assmann G, Schulte H. Relation of high density lipoprotein cholesterol and triglycerides to incidence of atherosclerotic coronary artery disease (the PROCAM experience). Am J Cardiol 1992;70:733-737.

[2] Hokanson JE, Autsin MA. Plasma triglyceride level is a risk factor for cardiovascular disease independent of high-density lipoprotein cholesterol level: a meta-analysis of population-based prospective studies. J Cardiovasc Risk 1996;3:213-219.

[3] Katsouras CS, Karabina SA, Tambaki AP, et al. Serum lipoprotein (a) concentrations and apoprotein (a) isoforms: association with the severity of clinical presentation in patients with coronary heart disease. J Cardiovasc Risk 2001;8(5):311-317 
[4] Anderson TJ, Meredith IT, Charbonneau F, et al. Endothelium - dependant coronary vasomotion relates to the susceptibility of LDL to oxidation in humans. Circulation 1996;93:1647-1650

[5] Durrington P, Sniderman A. (2002) Epidemiology and pathophysiology. In: Hyperlipidemia. Durrington P, Sniderman A (Eds). p. 29-31 Health Press, Oxford, UK

[6] Corti Ro, Fuster Va, Fayad Za, et al. Lipid lowering by simvastatin induces regression of human atherosclerotic lesions: two years' follow-up by high-resolution noninvasive magnetic resonance imaging. Circulation. 2002;106:2884-2887

[7] Nissen SE, Tuzcu ME, Schoenhagen P, Brown GB, Ganz P, Vogel RA, Crowe T, Howard G, Cooper CJ, Brodie B, Grines CL, DeMaria AN. For the REVERSAL investigators. Effect of intensive compared with moderate lipid lowering therapy on progression of coronary atherosclerosis. A randomized controlled trial. JAMA March 3, 2004;291(9).

[8] Toshima S, Hasegawa A, Kurabayashi M, Itabe H, Takano T, Sugano J, et al. Circulating oxidized low density lipoprotein levels. A biochemical risk marker for coronary heart disease. Arterioscler Thromb Vasc Biol 2000;20(10):2243-7.Holvoet P, Harris TB, Tracy RP, Verhamme P, Newman AB, Rubin SM, et al. Association of high coronary heart disease risk status with circulating oxidized LDL in the well-functioning elderly: findings from the Health, Aging, and Body Composition study. Arterioscler Thromb Vasc Biol 2003;23(8):1444-8.

[9] Ehara S, Ueda M, Naruko T, Haze K, Itoh A, Otsuka M, et al. Elevated levels of oxidized low density lipoprotein show a positive relationship with the severity of acute coronary syndromes. Circulation 2001;103(15):1955-60.

[10] Holvoet P, Collen D, \& Van de Werf F. Malondialdehyde-modified LDL as a marker of acute coronary syndromes. JAMA 1999;281(18):1718-21.

[11] Penny WF, Ben-Yehuda O, Kuroe K, Long J, Bond A, Bhargava V, et al. Improvement of coronary artery endothelial dysfunction with lipid-lowering therapy: heterogeneity of segmental response and correlation with plasma-oxidized low density lipoprotein. J Am Coll Cardiol 2001;37(3):766-74.

[12] Nishi K, Itabe H, Uno M, Kitazato KT, Horiguchi H, Shinno K, et al. Oxidized LDL in carotid plaques and plasma associates with plaque instability. Arterioscler Thromb Vasc Biol 2002;22(10):1649-54.

[13] Witztum JL, \& Steinberg D. Role of oxidized low density lipoprotein in atherogenesis. J Clin Invest 1991;88(6):1785-92.

[14] Steinbrecher UP, Parthasarathy S, Leake DS, Witztum JL, \& Steinberg D. Modification of low density lipoprotein by endothelial cells involves lipid peroxidation and degradation of low density lipoprotein phospholipids. Proc Natl Acad Sci USA 1984;81(12):3883-7. 
[15] Li D, Chen H, Romeo F, Sawamura T, Saldeen T, \& Mehta JL. Statins modulate oxidized low-density lipoprotein-mediated adhesion molecule expression in human coronary artery endothelial cells: role of LOX-1. J Pharmacol Exp Ther 2002;302(2):601-5.

[16] Steinberg D. Low density lipoprotein oxidation and its pathobiological significance. J Biol Chem 1997;272(34):20963-6.

[17] Steinberg D, Parthasarathy S, Carew TE, Khoo JC, \& Witztum JL. Beyond cholesterol. Modifications of low-density lipoprotein that increase its atherogenicity. N Engl J Med 1989;320(14):915-24.

[18] Ross R. Atherosclerosis--an inflammatory disease. N Engl J Med 1999;340(2):115-26.

[19] Bellosta S, Ferri N, Bernini F, Paoletti R, \& Corsini A. Non-lipid-related effects of statins. Ann Med 2000;32(3):164-76.

[20] Weber C, Erl W, Weber KS, \& Weber PC. HMG-CoA reductase inhibitors decrease $\mathrm{CD} 11 \mathrm{~b}$ expression and CD11b-dependent adhesion of monocytes to endothelium and reduce increased adhesiveness of monocytes isolated from patients with hypercholesterolemia. J Am Coll Cardiol 1997;30(5):1212-7.

[21] Jarvisalo MJ, Toikka JO, Vasankari T, Mikkola J, Viikari JS, Hartiala JJ, et al. HMG CoA reductase inhibitors are related to improved systemic endothelial function in coronary artery disease. Atherosclerosis 1999;147(2):237-42.

[22] Giroux LM, Davignon J, \& Naruszewicz M. Simvastatin inhibits the oxidation of lowdensity lipoproteins by activated human monocyte-derived macrophages. Biochim Biophys Acta 1993;1165(3):335-8.

[23] Aviram M, Rosenblat M, Bisgaier CL, \& Newton RS. Atorvastatin and gemfibrozil metabolites, but not the parent drugs, are potent antioxidants against lipoprotein oxidation. Atherosclerosis 1998;138(2):271-80.

[24] Li DY, Chen HJ, \& Mehta JL. Statins inhibit oxidized-LDL-mediated LOX-1 expression, uptake of oxidized-LDL and reduction in PKB phosphorylation. Cardiovasc Res 2001;52(1):130-5.

[25] Kwak BR, \& Mach F. Statins inhibit leukocyte recruitment: new evidence for their anti-inflammatory properties. Arterioscler Thromb Vasc Biol 2001;21(8):1256-8.

[26] Robinson JG, Smith B, Maheshwari N, \& Schrott H. Pleiotropic effects of statins: benefit beyond cholesterol reduction? A meta-regression analysis. J Am Coll Cardiol 2005;46(10):1855-62.

[27] Puccetti L, Pasqui AL, Pastorelli M, Bova G, Cercignani M, Palazzuoli A, et al. Timedependent effect of statins on platelet function in hypercholesterolaemia. Eur J Clin Invest 2002;32(12):901-8. 
[28] Holvoet P, Donck J, Landeloos M, Brouwers E, Luijtens K, Arnout J, et al. Correlation between oxidized low density lipoproteins and von Willebrand factor in chronic renal failure. Thromb Haemost 1996;76(5):663-9.

[29] Executive Summary of The Third Report of The National Cholesterol Education Program (NCEP) Expert Panel on Detection, Evaluation, And Treatment of High Blood Cholesterol In Adults (Adult Treatment Panel III). JAMA 2001;285(19):2486-97.

[30] Vasankari T, Ahotupa M, Toikka J, Mikkola J, Irjala K, Pasanen P, et al. Oxidized LDL and thickness of carotid intima-media are associated with coronary atherosclerosis in middle-aged men: lower levels of oxidized LDL with statin therapy. Atherosclerosis 2001;155(2):403-12.

[31] van Tits LJ, van Himbergen TM, Lemmers HL, de Graaf J, \& Stalenhoef AF. Proportion of oxidized LDL relative to plasma apolipoprotein B does not change during statin therapy in patients with heterozygous familial hypercholesterolemia. Atherosclerosis 2006;185(2):307-12.

[32] Liu ML, Ylitalo K, Salonen R, Salonen JT, \& Taskinen MR. Circulating oxidized lowdensity lipoprotein and its association with carotid intima-media thickness in asymptomatic members of familial combined hyperlipidemia families. Arterioscler Thromb Vasc Biol 2004;24(8):1492-7.

[33] Robbesyn F, Salvayre R, \& Negre-Salvayre A. Dual role of oxidized LDL on the NFkappaB signaling pathway. Free Radic Res 2004;38(6):541-51.

[34] Papathanasiou AI, Lourida ES, Tsironis LD, Goudevenos JA, \& Tselepis AD. Shortand long-term elevation of autoantibody titers against oxidized LDL in patients with acute coronary syndromes. Role of the lipoprotein-associated phospholipase A2 and the effect of atorvastatin treatment. Atherosclerosis 2008;196(1):289-97.

[35] Hulthe J, \& Fagerberg B. Circulating oxidized LDL is associated with subclinical atherosclerosis development and inflammatory cytokines (AIR Study). Arterioscler Thromb Vasc Biol 2002;22(7):1162-7.

[36] Harrison DG, Freiman PC, Armstrong ML, Marcus ML, \& Heistad DD. Alterations of vascular reactivity in atherosclerosis. Circ Res 1987;61(5 Pt 2):II74-80.

[37] Keaney JF, Jr., Guo Y, Cunningham D, Shwaery GT, Xu A, \& Vita JA. Vascular incorporation of alpha-tocopherol prevents endothelial dysfunction due to oxidized LDL by inhibiting protein kinase C stimulation. J Clin Invest 1996;98(2):386-94.

[38] Simon BC, Cunningham LD, \& Cohen RA. Oxidized low density lipoproteins cause contraction and inhibit endothelium-dependent relaxation in the pig coronary artery. J Clin Invest 1990;86(1):75-9.

[39] Frostegard J, Nilsson J, Haegerstrand A, Hamsten A, Wigzell H, \& Gidlund M. Oxidized low density lipoprotein induces differentiation and adhesion of human monocytes and the monocytic cell line U937. Proc Natl Acad Sci USA 1990;87(3):904-8. 
[40] Cushing SD, Berliner JA, Valente AJ, Territo MC, Navab M, Parhami F, et al. Minimally modified low density lipoprotein induces monocyte chemotactic protein 1 in human endothelial cells and smooth muscle cells. Proc Natl Acad Sci USA 1990;87(13):5134-8.

[41] Mehta A, Yang B, Khan S, Hendricks JB, Stephen C, \& Mehta JL. Oxidized low-density lipoproteins facilitate leukocyte adhesion to aortic intima without affecting endothelium-dependent relaxation. Role of P-selectin. Arterioscler Thromb Vasc Biol 1995;15(11):2076-83.

[42] Li H, Freeman MW, \& Libby P. Regulation of smooth muscle cell scavenger receptor expression in vivo by atherogenic diets and in vitro by cytokines. J Clin Invest 1995;95(1):122-33.

[43] Sawamura T, Kume N, Aoyama T, Moriwaki H, Hoshikawa H, Aiba Y, et al. An endothelial receptor for oxidized low-density lipoprotein. Nature 1997;386(6620):73-7.

[44] Archbold RA, \& Timmis AD. Modification of coronary artery disease progression by cholesterol-lowering therapy: the angiographic studies. Curr Opin Lipidol 1999;10(6): 527-34.

[45] Bellosta S, Bernini F, Ferri N, Quarato P, Canavesi M, Arnaboldi L, et al. Direct vascular effects of HMG-CoA reductase inhibitors. Atherosclerosis 1998;137 Suppl:S101-9.

[46] Rothe G, Herr AS, Stohr J, Abletshauser C, Weidinger G, \& Schmitz G. A more mature phenotype of blood mononuclear phagocytes is induced by fluvastatin treatment in hypercholesterolemic patients with coronary heart disease. Atherosclerosis 1999;144(1):251-61.

[47] Fuhrman B, Koren L, Volkova N, Keidar S, Hayek T, \& Aviram M. Atorvastatin therapy in hypercholesterolemic patients suppresses cellular uptake of oxidized-LDL by differentiating monocytes. Atherosclerosis 2002;164(1):179-85.

[48] Vasankari T, Ahotupa M, Viikari J, Nuotio I, Vuorenmaa T, Strandberg T, et al. Effects of statin therapy on circulating conjugated dienes, a measure of LDL oxidation. Atherosclerosis 2005;179(1):207-9.

[49] Mason RP, Walter MF, \& Jacob RF. Effects of HMG-CoA reductase inhibitors on endothelial function: role of microdomains and oxidative stress. Circulation 2004;109(21 Suppl 1):II34-41.

[50] Tsimikas S, Witztum JL, Miller ER, Sasiela WJ, Szarek M, Olsson AG, et al. High-dose atorvastatin reduces total plasma levels of oxidized phospholipids and immune complexes present on apolipoprotein B-100 in patients with acute coronary syndromes in the MIRACL trial. Circulation 2004;110(11):1406-12. 
[51] Balk EM, Lau J, Goudas LC, Jordan HS, Kupelnick B, Kim LU, et al. Effects of statins on nonlipid serum markers associated with cardiovascular disease: a systematic review. Ann Intern Med 2003;139(8):670-82.

[52] Mulder DJ, van Haelst PL, Wobbes MH, Gans RO, Zijlstra F, May JF, et al. The effect of aggressive versus conventional lipid-lowering therapy on markers of inflammatory and oxidative stress. Cardiovasc Drugs Ther 2007;21(2):91-7.

[53] Orem C, Orem A, Uydu HA, Celik S, Erdol C, \& Kural BV. The effects of lipid-lowering therapy on low-density lipoprotein auto-antibodies: relationship with low-density lipoprotein oxidation and plasma total antioxidant status. Coron Artery Dis 2002;13(1):65-71.

[54] Ky B, Burke A, Tsimikas S, Wolfe ML, Tadesse MG, Szapary PO, et al. The influence of pravastatin and atorvastatin on markers of oxidative stress in hypercholesterolemic humans. J Am Coll Cardiol 2008;51(17):1653-62.

[55] Miyagishima K, Hiramitsu S, Kato S, Kato Y, Kitagawa F, Teradaira R, et al. Efficacy of atorvastatin therapy in ischaemic heart disease - effects on oxidized low-density lipoprotein and adiponectin. J Int Med Res 2007;35(4):534-9.

[56] Sakabe K, Fukuda N, Wakayama K, Nada T, Shinohara H, \& Tamura Y. Effects of atorvastatin therapy on the low-density lipoprotein subfraction, remnant-like particles cholesterol, and oxidized low-density lipoprotein within 2 weeks in hypercholesterolemic patients. Circ J 2003;67(10):866-70.

[57] Zhu Q, McMaster J, Mymin D, Dembinski T, Hatch G, Choy PC, et al. Effects of atorvastatin treatment on the oxidatively modified low density lipoprotein in hyperlipidemic patients. Mol Cell Biochem 2000;207(1-2):9-17.

[58] Zhao SP, \& Zhang DQ. Atorvastatin enhances cellular uptake of oxidized LDL in adipocytes from hypercholesterolemic rabbits. Clin Chim Acta 2004;339(1-2):189-94.

[59] Schonbeck U, Gerdes N, Varo N, Reynolds RS, Horton DB, Bavendiek U, et al. Oxidized low-density lipoprotein augments and 3-hydroxy-3-methylglutaryl coenzyme A reductase inhibitors limit CD40 and CD40L expression in human vascular cells. Circulation 2002;106(23):2888-93.

[60] Hogue JC, Lamarche B, Tremblay AJ, Bergeron J, Gagne C, \& Couture P. Differential effect of atorvastatin and fenofibrate on plasma oxidized low-density lipoprotein, inflammation markers, and cell adhesion molecules in patients with type 2 diabetes mellitus. Metabolism 2008;57(3):380-6.

[61] Imanishi T, Hano T, Matsuo Y, \& Nishio I. Oxidized low-density lipoprotein inhibits vascular endothelial growth factor-induced endothelial progenitor cell differentiation. Clin Exp Pharmacol Physiol 2003;30(9):665-70. 
[62] Puccetti L, Sawamura T, Pasqui AL, Pastorelli M, Auteri A, \& Bruni F. Atorvastatin reduces platelet-oxidized-LDL receptor expression in hypercholesterolaemic patients. Eur J Clin Invest 2005;35(1):47-51.

[63] Van Himbergen T, Roest M, De Waart F, De Graaf J, Voorbij H, Van Tits L, et al. Paraoxonase genotype, LDL-oxidation and carotid atherosclerosis in male life-long smokers. Free Radic Res 2004;38(6):553-60

[64] Tani S, Dimayuga PC, Anazawa T, Chyu KY, Li H, Shah PK, et al. Aberrant antibody responses to oxidized LDL and increased intimal thickening in apoE-/- mice exposed to cigarette smoke. Atherosclerosis 2004;175(1):7-14

[65] Sasaki S, Kuwahara N, Kunitomo K, Harada S, Yamada T, Azuma A, et al. Effects of atorvastatin on oxidized low-density lipoprotein, low-density lipoprotein subfraction distribution, and remnant lipoprotein in patients with mixed hyperlipoproteinemia. Am J Cardiol 2002;89(4):386-9.

[66] van Tits LJ, Smilde TJ, van Wissen S, de Graaf J, Kastelein JJ, \& Stalenhoef AF. Effects of atorvastatin and simvastatin on low-density lipoprotein subfraction profile, lowdensity lipoprotein oxidizability, and antibodies to oxidized low-density lipoprotein in relation to carotid intima media thickness in familial hypercholesterolemia. J Investig Med 2004;52(3):177-84.

[67] van den Akker JM, Bredie SJ, Diepenveen SH, van Tits LJ, Stalenhoef AF, \& van Leusen R. Atorvastatin and simvastatin in patients on hemodialysis: effects on lipoproteins, C-reactive protein and in vivo oxidized LDL. J Nephrol 2003;16(2):238-44. 